\title{
Article
}

\section{Leveraging sponsorship to achieve consumer relationship objectives through the creation of 'marketing spaces': An exploratory study}

Donlan, Leah and Crowther, Philip

Available at http://clok.uclan.ac.uk/7178/

Donlan, Leah ORCID: 0000-0002-1320-2803 and Crowther, Philip (2012)

Leveraging sponsorship to achieve consumer relationship objectives through the creation of 'marketing spaces': An exploratory study. Journal of Marketing Communications. ISSN 1352-7266

It is advisable to refer to the publisher's version if you intend to cite from the work. http://dx.doi.org/10.1080/13527266.2012.684068

For more information about UCLan's research in this area go to http://www.uclan.ac.uk/researchgroups/ and search for <name of research Group>.

For information about Research generally at UCLan please go to http://www.uclan.ac.uk/research/

All outputs in CLoK are protected by Intellectual Property Rights law, including Copyright law. Copyright, IPR and Moral Rights for the works on this site are retained by the individual authors and/or other copyright owners. Terms and conditions for use of this material are defined in the policies page. 
Leveraging sponsorship to achieve consumer relationship objectives through the creation of 'marketing spaces': An exploratory study

Philip Crowther

Sheffield Business School

Sheffield Hallam University

City Campus

Sheffield

S1 1WB

E-mail: philip.crowther@shu.ac.uk

Tel: 01142253145

Fax: 01142255268

Author Biography:

Philip Crowther is a Senior Lecturer in Event Management at Sheffield Hallam University, United Kingdom. He has considerable industry experience in event management within the leisure and tourism industries. Philip's main research interests are in the area of events as live communications.
Dr Leah Donlan*

University of Central Lancashire

School of Sport, Tourism and The Outdoors

Preston

Lancashire

PR1 2HE

United Kingdom

E-mail: LDonlan@uclan.ac.uk

Tel: 01772894239

Fax: 01772892927

Author Biography:

Dr Leah Donlan is a Lecturer in Sports Marketing at the University of Central Lancashire, Preston, United Kingdom. She was awarded her $\mathrm{PhD}$ from Sheffield Hallam University in 2008 and her main research interests are in the use of sponsorship and other marketing communications to build successful brands.

*Author responsible for correspondence and correction of proofs 


\title{
Leveraging sponsorship to achieve consumer relationship objectives through the creation of 'marketing spaces': An exploratory study
}

\begin{abstract}
This paper explores the emergence of sponsorship-linked events as a strategy to leverage relational outcomes through sponsorship investment. The growing use of sponsorship-linked events reinforces the need to understand the potential of such leverage strategies, thus the findings contribute to the body of literature on effective sponsorship practices. Findings from semi-structured interviews with Sponsorship and Marketing Managers suggest a shifting orientation among sponsors towards the pursuit of relational objectives. The privileged access to consumers afforded through sponsorship allows sponsors to manufacture opportunities to create intimacy with customers through sponsorshiplinked events in relaxed, comfortable environments; thus sponsorship-linked events are positioned as a rich environment to add value to consumer-brand interactions and achieve relational objectives. Hosting specifically designed events affords sponsors an increased modicum of control over consumer-brand experiences in sponsorship environments characterised by a lack of control over sponsored property actions. However, this control may be eroded by social media technologies, which facilitate consumer-consumer communication around sponsorship-linked events. Social media, however, is proposed as a useful tool to elicit consumer feedback, addressing the misalignment between current sponsorship evaluation practices and emergent relational objectives revealed in the empirical findings. Therefore, successfully activating the sponsorship-linked marketing space demands an integrated and strategic approach.
\end{abstract}

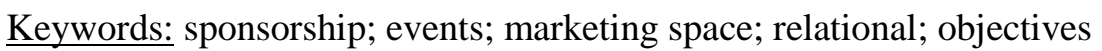




\section{Introduction}

Sponsorship has matured rapidly over recent decades. This has created a situation where organisations must adopt wider and more integrated strategies to fully exploit their sponsorship investment. The exploitation, or activation, of the sponsorship can be achieved through various strategies. An emergent strategy in this respect is the creation of many and varied events as purposeful vehicles through which to leverage the sponsorship. These comprise a variety of marketing (or experiential) event platforms (Crowther, 2010; Wood, 2009) ranging from themed parties, to more intimate conferences and seminars. Such sponsorship-linked events are employed by both B2B, for example GE's Olympic-themed business events (General Electric, 2008), and B2C brands, for example, the Cadbury's Spots v Stripes Race Season events (Spotsvstripes, 2011). The domain of event sponsorship represents an area which has received much academic scrutiny (Chanavat et al, 2010; Ashill et al, 2001; Quester and Farrelly, 1998); however the adoption of sponsorship-linked marketing events as a leverage strategy is an emergent and under-researched area. As the use of sponsorship-linked marketing events increases, so there is a contingent need to interpret their relative worth and evaluate relevant managerial implications, which is an overarching emphasis of this paper.

An exploratory approach is adopted, with the paper explicitly aiming to explore how sponsorshiplinked events can be used as a leverage tool to achieve relational outcomes, such as building consumer relationships (Dolphin, 2003) and brand loyalty (Levin, Beasley and Gamble, 2004). Underpinning this is the notion that the event should elicit positive consequences for the consumer and therefore value is created with the customer becoming better off in some respect (Grönroos and Ravald, 2011). Through the use of semi-structured interviews with Marketing and Sponsorship Managers in UKbased national and multinational organisations across a range of industries and sponsorship settings, this paper explores, from a managerial perspective, the rationale for using sponsorship-linked marketing events. In light of the pressing realisation of the value and importance of sponsorship 
leverage (Cornwell, Weeks and Roy, 2005), this paper contributes to the growing body of literature on effective sponsorship practices and thus can inform both practical sponsorship strategies and further empirical academic research in the area of optimising sponsorship effectiveness in a marketing environment characterised by a shift from a transactional to a relational orientation.

To help interpret the contribution and dynamics of sponsorship-linked events, the paper draws upon the marketing space framework (Crowther, 2010) in the examination of sponsorship leverage strategies. Underpinning the framework, shown in Figure 1, is the underlying notion of 'marketing space' (Crowther, 2010). This depicts the event as a unique physical and temporal space which can be perceived as 'time out of time' (Getz, 2007), a fusion, for the attendee, of the sacred and profane (Belk, Sherry, and Wallendorf, 1989), rich in relational opportunity. The event space is thus conceptualised as a transient reality where an organisation comes together physically, and in a planned manner, with a gathering of existing and future customers, clients, and wider stakeholders; palpably dissimilar to other communication approaches. Therefore, in the case of sponsorship-linked events, the sponsorship enables this congregation to occur, facilitating proximity and intimacy between an organisation and its consumers. Implicit in the ensuing discussion is that given the imperative for organisations to engage with consumers ( Grönroos and Ravald, 2011), the creation of this space is apposite, permitting opportunity for a cocreation of value (Vargo and Lusch, 2008) between the participating actors, focal organisation to consumer, but also consumer to consumer (Harris and Baron, 2004). Furthermore, the event based strategy rightfully transcends the physical event and is inclusive of pre- and post-event communication, depicted as augmented space in Figure 1. The event strategy should thus be infused by the strategic sponsorship objectives and carefully integrated with wider marketing activities and customer experience management.

[Insert Figure 1 about here]

Realising the opportunity implied in the notion of marketing space impinges upon many factors, not least the event planning and delivery. The marketing space framework depicts the contingent 
relationship between the event experience of participants and the underlying objectives, design, delivery, and evaluation on the part of the focal organisation. Given that an event is inherently experiential, the design and delivery need to be purposeful to achieve relational outcomes and more holistically integrate with the wider sponsorship strategy. Given the experiential nature of events, all aspects of the process have the potential to enhance or diminish the relational outcomes (Crowther, 2010).

Consequently, in line with the stages of the marketing space framework, and adopting an exploratory approach, this paper will address the following research questions:

(RQ1) What (relational) objectives are being pursued by sponsors?

(RQ2) What event design and delivery approaches are sponsors adopting in the creation and management of sponsorship-linked events, and what factors impact on the effectiveness of these approaches in achieving relational objectives?

(RQ3) How and to what extent are sponsors evaluating sponsorship-linked events against their relational objectives?

\section{Sponsorship leverage}

Recent years have seen considerable growth in sponsorship, with IEG reporting global sponsorship expenditure of $\$ 46.6$ billion in 2010 (Reuters, 2011). Early growth in sponsorship was driven partly by advertising clutter (Roy and Cornwell, 2004) but the sponsorship marketplace itself is now becoming increasingly cluttered (Meenaghan, 1998). Therefore, sponsors need to be able to cut through the 'noise' to reach and engage with consumers and other stakeholders. As such, sponsors must go beyond mere signage (Skildum-Reid, 2003) and strategically and creatively leverage their investment.

Brand awareness (Verity, 2002) and brand image benefits (Roy and Cornwell, 1999) are still frequently cited objectives of sponsorship. However, in line with wider shifts in marketing 
orientations towards a relational paradigm (Grönroos, 1994), Skildum-Reid (2003) advocates a move to what she terms 'last generation sponsorship', where the focus is not on what brands can get out of sponsorship but on what they can offer their customers through sponsorship, consistent with the tenet of doing things for and with customers (Vargo and Lusch, 2004). This view is in line with the emerging interest in viewing sponsorship from a relational or network perspective (Olkkonen, Tukkanen and Alajoutsijärvi, 2000) rather than as a one-way communications medium. As such, sponsorship is increasingly being used to achieve objectives of building connections with customers (Farrelly, Quester and Burton, 2006), creating customer conversations (Kumar, 1997) and logically as a form of customer consultation (Haeckel, 1999). These objectives can be realised through the creation of sponsorship-linked brand experiences (Donlan, 2010), consistent with events.

To date, there has been little academic research exploring the impact of sponsorship on creating, building, and sustaining customer relationships. Clark et al (2003) examined the use of sponsorship to move B2B customers through the relationship life cycle; however the focus of this study was very much concerned with sales as a direct outcome of business relationships. A study in the USA by Levin, Beasley and Gamble (2004) found greater brand loyalty towards NASCAR sponsors among fans of the sport, but this study did not extend to examining the relationships built between sponsors and fans through the sponsorship arrangement. Therefore, this paper provides a more focussed examination of the nature of relational objectives being pursued by sponsors.

Meenaghan (1991:8) refers to sponsorship as a 'mute, non-verbal medium', which needs to be effectively leveraged (Cornwell, 1995) in order to maximise its ability to achieve a range of marketing objectives. The lack of success of much previous sponsorship has been blamed on sponsors' failure to support and integrate their sponsorships with appropriate advertising, PR and other promotional activities (Erdogan and Kitchen, 1998). Davies and Tsiantas' (2008) Optimal Leveraging Activity model recommends a relationship-oriented approach for high involvement brands, targeting customer retention through customer contact and PR activities. The creation of sponsorship-linked events is an effective means by which sponsorship can be leveraged to engage consumers on a behavioural level 
(Whelan and Wohlfeil, 2006); this strategy, for example, was employed to good effect by Vodafone New Zealand through the creation of brand experiences around its rugby sponsorship (Cliffe and Motion, 2005).

\section{Utility of marketing events}

Prior to examining the interrelationship between sponsorship and events, and its efficacy for achieving relational outcomes, it is useful to consider the virtue and utility of marketing events per se. Planned events provide marketing practitioners with a versatile engagement platform (Ramaswamy, 2011) that is highly relevant to the contemporary marketing environment. The inherent qualities of events, such as relational (Grönroos, 1990), participative (Vargo and Lusch, 2004), and experiential (Parsons and Maclaren, 2009) mean they provide an apposite weapon in the modern marketer's quest to build deeper and more meaningful relationships with consumers. The intimacy and interactivity in the event space and the voluntary and active involvement of attendees further augments the relational virtue of events, promoting a participative and collaborative experience. Unequivocally, this discussion juxtapositions events with more traditional sponsorship leverage strategies where the recipient is less active, or even inactive, in the communication process (Duncan and Moriarty, 1998). The above points combine to suggest that events offer the Sponsorship Manager something different vis à vis other, more traditional, communication platforms.

\section{Marketing events and sponsorship}

When adopting events as a leverage strategy, Sponsorship Managers are indulged with a rich and diverse selection of marketing event platforms (Crowther, 2010). Wood (2009) offers an extensive typology of what Wood and Masterman (2007) term experiential marketing events. This includes forms such as created events, for example, bespoke sponsorship-linked events such as $\mathrm{O}_{2}$ 's Scrum in the Park, which leveraged its sponsorship of England Rugby. These platforms are demonstrated in Figure 2 below. Each event type, or marketing event platform (Crowther, 2010), has a distinct charm 
and challenge, thus lending itself to the achievement of specific outcomes, and combinations of outcomes; therefore, the selection of the right event platform(s) impinges upon the specifics of the sponsorship strategy and the characteristics of the participant consumers.

[Insert Figure 2 about here]

Sponsorship is usefully viewed as a hook (Sleight, 1989) around which other marketing communications activities can be hung. Similarly it can be suggested that the profile, access, and credibility afforded through sponsorship provide a gateway through which to cultivate and augment relationships with existing and desired customers, clients, and wider stakeholders (Hartland, Skinner and Griffiths, 2005). Marketing events constitute a fitting vehicle through which to realise that opportunity, for example, they can be seen to particularly lend themselves to the achievement of relational objectives with key accounts, given their personalised and experiential makeup (Hartland, Skinner and Griffiths, 2005).

An endemic concern for sponsors is that the use of sponsorship as a brand, or customer relationshipbuilding tool, carries inherent risk. Directly connecting your brand with another concedes some control over transferred or shared brand associations as sponsors are dependent on the actions of sponsored properties (Meenaghan, 1991; Westberg, Stavros and Wilson, 2008). The increasing use being made of sponsorship-linked events (Donlan, 2010), is purposefully seen in this context, as sponsors seek to leverage their associations whilst asserting a degree of control over the communication of their brand to future and existing consumers. Grönroos and Ravald (2011) talk of the importance of brands finding a way into the customer's arena for value creation; therefore, the privileged access to consumers afforded through sponsorship allows sponsors to manufacture opportunities to create intimacy with customers through sponsorship-linked events in environments where the consumers feel comfortable. The use of events in this way creates a marketing space within which sponsorship objectives can be achieved with an increased modicum of control over the experience of consumers. 
An increasingly relevant topic for consideration is the proliferation of social media technologies such as Twitter, Facebook and Flickr, and their application and influence in the context of events. Social networking technology facilitates not only organisation-consumer and consumer-organisation communication around an event, but also consumer-consumer communication (Chu and Kim, 2011), over which event organisers have lesser control (Mangold and Faulds, 2009). Notably the relational impact of the event reaches beyond the physical attendees. Thus, while the creation of sponsorshiplinked events allows sponsors a greater modicum of control over the physical event experience, that control can be eroded by the greater consumer-consumer communication which has been facilitated by social networking technologies, which can be updated in real-time, for example, by event attendees tweeting whilst at an event. However, it is possible for event organisers to attempt to facilitate these consumer-consumer interactions by providing a platform for the interactions (Mangold and Faulds, 2009), for example, the creation of a Twitter hashtag for conference delegates to use when tweeting about the event, accompanied by a giant screen displaying the corresponding Twitter feed at the conference.

There are obvious potential benefits from the use of these tools around sponsorship-linked events, not least of which is in evaluation (Poynter, 2008) of the event experience. The proliferation of social networking tools places heightened pressure on marketers to optimise all areas of the event experience in order to reduce the potential for negative e-word-of-mouth (eWOM) and tap into the benefits of positive eWOM. Delivering a positive sponsorship-linked event experience becomes more important in such a climate, especially given that the effect of eWOM has been found to be greater for negative eWOM than for positive eWOM, particularly in the case of experience goods (Park and Lee, 2009). Therefore the growth in consumer-consumer communication and its potential to impact upon the event experience have only added to the already growing imperative for sponsors to evaluate sponsorship-linked events in terms of their contribution to achieving stated objectives. As such, the paper will briefly explore the current practices of sponsors in evaluating sponsorship-linked events against their relational objectives. 
The above discussion and review of literature have demonstrated the potential virtues of events as a sponsorship leverage strategy. They also provide an insight into the process for realising the efficacy of marketing events for the Sponsorship Manager. The following section will outline the methodology employed, before moving on to discuss the findings from empirical research with Marketing and Sponsorship Managers.

\section{Methodology}

In line with the exploratory nature of the study, a qualitative methodology was employed, making use of semi-structured interviews with marketing and sponsorship practitioners. The aim of this study is to examine the use of events as a sponsorship leverage strategy; therefore interviews with sponsorship practitioners allow us to explore the rationale for using marketing events from a managerial perspective. Further research empirically testing the impact of these leverage strategies is advocated; however, it is critical to explore the practitioner perspectives, rationales and objectives prior to assessing the success of leverage strategies from a consumer perspective.

\section{Respondent sample}

Telephone and face to face interviews were conducted with ten Sponsorship or Marketing Managers (or equivalent) in UK-based companies actively engaged in sports sponsorship. Respondents were purposively sampled based on the company's involvement in sports sponsorship, with the final sample size determined by availability and willingness to take part in the research. The quotes included in the discussion below were selected based on the insight they offer in exemplifying the use of sponsorship-linked marketing events across a range of sponsorship contexts. While there is some imbalance in the contributions of individual respondents based on the selected quotes, the discussion is informed by the wider issues raised by all interviewees. The sponsoring firms represent a broad range of $\mathrm{B} 2 \mathrm{~B}$ and $\mathrm{B} 2 \mathrm{C}$ markets, including telecommunications, travel, financial services and 
professional services. The identities of sponsoring brands are not revealed for reasons of confidentiality. At the time of interviewing, all of the brands were involved in sponsoring elite-level sport, including events, teams and individual athletes, with a well-known national or international profile.

\section{Interview structure and analysis}

As all sponsors operate in different sponsorship settings and product/service industries, there are considerable differences between brands in terms of objectives and activation tactics. Therefore, a semi-structured interview format was deemed most appropriate in order to capture the differing sponsorship-linked realities in the words of the practitioners themselves. The interviews covered a range of sponsorship-related topics, including those of objectives and leverage activities reported in this paper. Within this study, questioning in relation to sponsorship objectives was initially very open to allow respondents to freely express the full range of corporate, marketing, media, personal and relational objectives (Hartland, Skinner and Griffiths, 2005) being pursued. Contingent on the responses obtained, subsequent questions probed specific objectives, particularly those of a relational nature. This approach was adopted, in line with RQ1, to more accurately capture the range and nature of objectives pursued through sponsorship, rather than pre-empting a relational focus. The interviews lasted between 25 and 45 minutes each and took a semi-structured format to allow for further probing on specific questions as dictated by the nature and direction of the interview content. There are obvious limitations to semi-structured interviews, notably that they can pre-structure the direction of enquiry within the frame of reference of the interviewer, rather than that of the interviewee (Jones, 2004). However, given that respondents were selected in their professional capacity, the aim of the research was to identify sponsorship practices by organisations, rather than the specific viewpoints of individuals (Flick, 2002). Nonetheless, consideration must be given to this limitation when interpreting findings; further research is advocated, using less structured interviewing techniques, particularly with event attendees, to fully explore the interactive, relational capacity of sponsorshiplinked events. 
In order to allow respondents to provide full and accurate answers, questions and outline topics for consideration were circulated prior to the interviews. The purpose of the pre-circulated questions was to act as a prompt, allowing respondents to reflect on their sponsorship strategies and tactics in advance of the interview. An example of the pre-circulated questions is provided in Appendix 1. Interviewing experts, as is the case in this study, often results in respondents offering a more guarded or corporate response (Odendahl and Shaw, 2002), which may be heightened by circulating questions in advance, as this allows respondents to consider their responses more carefully than if questions were asked spontaneously. However, the prior circulation of questions was requested by several respondents and, as such, was deemed necessary to elicit cooperation from interviewees. Interviews were recorded and transcribed verbatim; transcripts were subjected to thematic analysis using NVivo 2.0.

\section{Results and discussion}

\section{RQ1: Objectives pursued by sponsors}

The specific notion of achieving relational objectives through the cultivation of event spaces is endorsed by several Sponsorship Managers, with one claiming that 'from a sponsorship standpoint you have many more opportunities in terms of really interacting with people', (Interviewee 2) while another reported that 'we want to use that great access to talk to people and to convert them...to [our brand'] (Interviewee 3). Long seen as a tool suitable primarily for achieving objectives of awareness and image benefits, respondents reported an increasing acknowledgement of sponsorship's ability to affect 'brand affinity' (Interviewee 3) and 'drive further loyalty' (Interviewee 1). The use of events as a sponsorship leverage strategy facilitates such objectives by voluntarily and participatively engaging customers and allowing brands to '[link] up with the passions in people's lives' (Interviewee 3). Thus, sponsorship-linked events can be a means to 'develop existing relationships and to help facilitate new relationships' (Interviewee 4). As such, in response to research question 1, we see that 
the opportunities afforded to sponsors through the creation of sponsorship-linked events allow them to reach out to both new and existing customers, and also wider stakeholders. While many other objectives, which can be considered to be more closely aligned with a transactional paradigm, were also expressed, for example, 'increased brand awareness' (Interviewee 5), the findings from this research indicate that there is a shift towards an acknowledgement of the role sponsorship can play in achieving relational objectives, particularly when an event-based leverage strategy is adopted.

Decisions about the design and delivery of an event should be underpinned by explicit event objectives, which are in turn informed by the wider sponsorship strategy; as expressed by Interviewee 1: 'it will be an integrated part of everything we do.' Therefore the experience facilitated for the attendee is inextricably linked to the strategic sponsorship objectives and integrated with other forms of communication. A key question is how objectives can be achieved through creative and purposeful design of the marketing spaces. The creation of marketing spaces around a particular sponsorship through the development of brand-specific events is not accidental, but is rather a planned leverage strategy. As Interviewee 6 advocated, 'you need to think through your event format and design' in order to best achieve your objectives. Brands need to therefore select appropriate event platforms and designs to best achieve their specific objectives; events should be infused with strategic intent and not ad hoc operational convenience.

\section{RQ2: Nature and effectiveness of sponsorship-linked event design and delivery}

A pivotal decision in the event design process is to select which event platform to utilise, determined by the nature of the consumer and the specific outcomes required. A customary example, particularly in the case of sports sponsorship, is the adoption of hospitality events. The attractiveness of hospitality is widely reported and was echoed by several sponsors in this study, particularly among B2B brands. Notably, however, the interviews suggested a changing landscape with evidence of a shift in the corporate climate, indicating a possible move away from the predominance of hospitality as the primary sponsorship activation tool. Interviewee 7 talked about 'overt hospitality and entertainment 
being a thing of the past in influencing business to business buyers.' He even went so far as to suggest that, 'hospitality invitations I accepted 10 years ago would probably get me a warning or even the sack if I accepted them now'. The protocol has become that many corporate organisations would insist on you formally declaring your interest if you were to attend a sponsorship event at the behest of a supplier.

The above emphasises the need for Sponsorship Managers to consider the full range of options in deciding which event platform(s) to adopt; the implication being that platforms with a less overt focus upon hospitality and entertainment, such as learning, recognition, and charitable events, are increasingly relevant. Each of these would still include entertainment and hospitality; however they would be perceived as secondary to more laudable outcomes.

Aligned with earlier discussion relating to its unpredictable nature, Interviewee 2 highlighted the risks associated with sponsorship, particularly of athletes getting injured or for some other reason being unable to play at a scheduled event. Equally, sponsorship carries risks in terms of negative image transfer to sponsors in case of athlete/team/organisation transgressions or poor performances. These elements of the sponsorship relationship are largely outside of the control of the sponsor; therefore it is incumbent upon sponsors to leverage their sponsorship in a way which affords them maximum control over at least part of the consumer's sponsorship experience. Events allow brands to talk to consumers in a conducive environment and thus open up possibilities for greater consumer-brand interactions. In the words of Interviewee 1:

'[Sponsorship allows us to talk to consumers] that wouldn't necessarily engage with [the brand]. [The sponsored event] gives us permission to talk to these individuals about something that they're engaged and passionate about.'

Thus, sponsorship-linked events can provide a catalyst for brands to hold conversations with consumers in a comfortable and more controlled environment, where the sponsoring organisation has an increased modicum of control over the event experience. 
By creating an event around the sponsored property, sponsors can closely facilitate the interactions that consumers have with their brands. As Interviewee 3 expressed: 'what we do is we put on great experiences.' This simple statement sums up the power of sponsorship-linked events in that they offer the opportunity for brands to be creative in enhancing the spectator experience through interactions with the brand. One risk in employing such tactics as celebrity meet and greets is that sponsorship-linked events become attractive to relationship exploiters, who take all available advantages from relationship offers without demonstrating brand loyalty (Piercy, 2009). Therefore, the centrality of the brand in the event design becomes crucial. Well-executed sponsorship-linked events not only allow opportunities for showcasing products and services but also afford brands the opportunity to experientially showcase their brand ethos in a way which adds value to the overall experience of attending the wider sponsored event:

'[The sponsorship-linked event] really demonstrates who we are as a brand...[It] gives us an opportunity to demonstrate what our [product] is, what our [staff] are like and get people to experience the [brand] experience as a fantastic event that they'll really enjoy.' (Interviewee 1)

The ability of sponsorship to facilitate the creation of bespoke marketing spaces thus allows brands the opportunity to achieve relational outcomes, and specifically exercise control over elements of the brand messages received. The delivery stage is critical to the success of any event-based strategy as it is here where consumers truly interact with and experience the brand. Therefore, a good event-based sponsorship leverage design must be underpinned by creative and proficient event delivery.

Event experience is determined by a range of tangible and intangible factors that expose the attendee to the brand. The core components of the event such as venue, entertainment, catering, and speakers are persuasive, but peripheral aspects are also telling. One strong theme that emerged from the interviews was that in the context of creating sponsorship-linked marketing spaces, a key to successful delivery is to tap into fan (attendee) passions (interests) in order to create an experience that money cannot buy. There is considerable evidence from the brands included in this study of the use of events 
to leverage sponsorship activities, in the form of roadshows, trophy tours, fan days and exclusive parties. Such events provide sponsors with the opportunity to, as Interviewee 6 expresses, 'gain intimacy with customer $[s]$ ', engaging with them in an interactive fashion, providing an experience that cannot easily or possibly be replicated. Such an approach is exemplified in the case of one sponsor, which makes extensive use of events to leverage its sports sponsorships to great success: 'we...provide [preferential] experience[s] if they're...customers. So...customers who turn up...can get access to a... branded marquee and [free refreshments]. You get the chance to have a Q\&A with [team] players after the match...it's a kind of a VIP area for...customers and hundreds or even thousands of those customers can go through and experience that and touch and engage with the brand in and around our [sport] property... So...customers going to [sponsored event/venue] will get much more than just a [promotion-linked] ticket...they can get that little bit extra that would make you feel extra special and then of course there's a huge amount for...engaging people and keeping people with the brand because they feel valued and loved and rewarded for their loyalty.' (Interviewee 3)

The creation of sponsorship-linked events for this brand revolves around existing customers, with the aim of using the sponsorship to elevate the spectator experience. Therefore, such events, by augmenting the sports event experience, can be used to nurture brand loyalty. However, such creative event executions can also achieve customer acquisition objectives by creating 'brand envy' (Interviewee 3) among non-customers who do not gain access to the branded event experience. The unique and perishable character of events is persuasive in this respect, with event elements being crafted so as to create desire and a feeling of exclusivity. The challenge is of course manifest, as a number of the interviewees emphasised, if you are going to deliver a physical event you have to get it right, provide 'great experiences' (Interviewee 3) and 'exceed expectations' (Interviewee 6).

The diversity of event platforms available to brands as a sponsorship leverage strategy affords opportunities not only to consumer brands but also B2B sponsors seeking to achieve relational objectives. The creation of a 'client event' where 'athletes come along and talk to...clients about what 
it is that [the brand] is doing to make a difference' (Interviewee 4) allows B2B brands to engage in conversations with customers in terms of how a particular sponsorship can add value to the brand's product/service offerings. For example, a speech by a prominent athlete at such an event can spark 'conversation between [the brand's] people and the clients and they can talk about a specific piece of work [being done for the sponsored event] that...might be relevant to that client' (Interviewee 4). As with B2C brands, sponsorship-linked events create an opportunity for B2B brands to talk to clients in different contexts; more relaxed and intimate environments in which they feel comfortable.

Therefore, once again it is the combination of interactive experiences and adding value to customers that positions events, in a variety of guises, as an opportune sponsorship leverage approach.

A cited sponsorship objective of one of the brands in the study was to create 'talkability'(Interviewee 8), thus the use of social media to create virtual sponsorship-linked events meshes perfectly with such goals. Increasingly, it is evident that sponsors are turning towards social media platforms to leverage their sponsorship as their target markets become avid users. In the words of Interviewee 3, 'they're online and they're engaging with their friends in these environments.' This has the impact of building communities with the brand at the heart of the process. The growth of eWOM facilitated by social media can also give both physical and virtual sponsorship-linked events a lifespan beyond the actual duration of the event, also reinforcing and extending the 'brand envy' (Interviewee 3) created through the events themselves. The potential negative implications of eWOM need to be balanced with the positive consequence. Linking with the statements made above by Interviewees 1 and 3, while brands will lose some control as a result of such technologies, the imperative is to infuse the event with positive brand values and deliver value-adding experiences which will delight attendees.

\section{RQ3: Nature and extent of sponsorship-linked event evaluation against relational objectives}

For events to be established as a recognised sponsorship leverage strategy it is necessary to evaluate the outcomes with a coherent link back to the originally stated objectives. Therefore, there is an imperative for sponsors to develop evaluation tools which effectively tap, in the context of this paper, 
into relational variables. Evidence from the sponsors involved in this study indicated that evaluation is still an underdeveloped area, with Interviewee 6 stating that difficulty of measurement is actually an impediment to the adoption of events. Reflecting that there are real and obvious costs associated with staging events, it is much more difficult to quantify the value gained. Interviewee 3 elaborates further:

'we don't do enough evaluation and I'd love to do more but it's often a product of time and budget...We probably should do more...I think it's a hugely important aspect of what you do because especially in the current climate where you're very accountable for how you're spending your marketing dollar, everyone's checking return on investment and your sponsorship is incredibly important.'

There is therefore an appreciation among sponsors of the importance of the evaluation stage, but evidence from the interviews suggests that most brands are evaluating their sponsorship via brand trackers, which can provide insight into lower order objectives of awareness and image enhancement but which are limited in their ability to assess relationship development because of their largely quantitative nature.

One interviewee revealed that the brand undertakes qualitative research at events, looking at 'awareness and affinity and what [attendees] thought of the event' along with whether the event would 'increase [customer] preference towards [the brand]' (Interviewee 3). Given the pursuit of relational objectives, such evaluation methods are advocated in order to probe deeply into the impact of sponsorship-linked events on consumers. There is increasing scope, as with the event delivery stage, to use new technologies including social media at the evaluation stage. For example, sites such as Twitter and Facebook can be used by sponsors to elicit real-time, cost-effective feedback on the event. Interviewee 6 reflected how increasingly 'people live their lives on line' thus facilitating a method of assessing eWOM. The area of evaluation appears to still lag behind those of objectives, design and delivery in terms of the holistic management of sponsorship-linked events. Current evaluation practices are often misaligned with the emergent relational objectives. Notably an 
effectively integrated social media strategy around the event may provide an opportunity to capture feedback and feedforward in the context of relational outcomes.

\section{Conclusion}

This paper has explored the potential of sponsorship-linked events to achieve relational objectives, identifying the importance of taking a holistic approach to the integration of these events into wider sponsorship strategy, and specifically their design, delivery and evaluation. The interviews with sponsorship and marketing practitioners suggested a shifting orientation among sponsors towards the pursuit of relational objectives such as customer relationship development and building brand loyalty, alongside some of the more traditional, transactional-oriented sponsorship objectives (RQ1).

One advantage in the adoption of sponsorship-linked marketing events as a leverage strategy, is that it permits the sponsor an increased modicum of control over the consumer experience, which is prized in a sponsorship reality where, for example, uncertainty associated with on-pitch results and team/player behaviour increases unpredictability. It is evident that approaches to sponsorship-linked event design and delivery vary in scale and nature between sponsors, although the interviews revealed a collective understanding among practitioners of the importance of creating positive and meaningful event experiences as a prerequisite to facilitating new and enhanced relationships (RQ2). However, the degree of control that sponsors have over sponsorship-linked events is eroded to a certain degree by the proliferation of social media technologies, which facilitate instant consumer-consumer communication about sponsors and events. Importantly, this instant communication potential further reinforces the imperative to create superlative experiences to minimise the potential for negative eWOM. There is evidence from this study that there remains a degree of misalignment between evaluation practices and objectives around sponsorships as the objectives shift towards a more relational orientation (RQ3). It is here, again, where the use of social media technologies can help sponsors in measuring consumer event experiences in real-time and also in extending the eWOM around an event well beyond its physical duration. 


\section{Implications for theory and practice}

As we see a shift in focus on sponsorship from a transactional to a relational approach, this paper contributes to the growing body of literature on effective sponsorship practices, positioning (well leveraged) sponsorship firmly within the relational paradigm. The findings indicate that events offer many benefits to sponsors in seeking to achieve relational objectives, and they thus represent a valuable tool in the leverage armoury of sponsoring brands. Through the access to desirable properties afforded through sponsorship, brands can manufacture opportunities to create marketing spaces to facilitate intimacy and interaction with consumers, creating event experiences that add value, and thus underpinning a more lasting relationship with the organisation. Sponsorship-linked events thus provide Sponsorship and Marketing Managers with an appealing tool that, through careful planning and integration, can sustain and enhance relationships by creating 'space' in which value can be created. The experiential, participative, and targeted qualities of events afford a marketing space that is rich in potential; however, as the paper has demonstrated, successfully realising this potential, or activating the marketing space, demands an integrated and strategic approach.

\section{Limitations and areas for future research}

This exploratory study draws on data from interviews with ten Sponsorship/Marketing Managers in UK-based organisations. Therefore, a limitation of the study is the relatively small sample size. While efforts were made to ensure that participants represented a range of both product/brand categories and sponsored properties, given the diverse nature of sponsorship, care should be exercised when generalising from the findings. This research explored the use of events as a sponsorship leverage strategy in the UK; therefore given the differences in the use and development of sponsorship in other markets, no claim is made of generalizability beyond the UK context. Consequently, further investigations into the use of events as leverage strategies are advocated. 
There is also a need to build upon this research with a closer examination of the use of different event platforms to achieve a diverse range of objectives. Similarly, building upon the research presented in this paper, which looks at marketing events as a sponsorship leverage strategy from the managerial perspective, there is a need to empirically explore the effectiveness of marketing spaces as a leverage strategy from a consumer perspective.

\section{References}

Ashill, N. J., Davies, J. and Joe, A. (2001). Consumer attitudes towards sponsorship: A study of a national sports event in New Zealand. International Journal of Sports Marketing \& Sponsorship, 2 (4), 291-313.

Belk, R., Sherry, J., and Wallendorf, M. (1989). The sacred and the profane in consumer behaviour: theodicy on the odyssey. Journal of Consumer Research 16 (1), 1-38.

Chanavat, N., Martinant, G. and Ferrand, A. (2010) Brand Images Causal Relationships in a Multiple Sport Event Sponsorship Context: Developing Brand Value through Association with Sponsees. European Sport Management Quarterly 10 (1), 49-75.

Chu, S-C., and Kim, Y. (2011) Determinants of consumer engagement in electronic word of mouth (eWOM) in social networking sites. International Journal of Advertising 30 (1), 47-75.

Clark, J., Lachowetz, T., Irwin, R.L., and Schimmel, K. (2003) Business-to-Business Relationships and Sport: Using Sponsorship as a Critical Sales Event, International Journal of Sports Marketing \& Sponsorship 5 (2), 129-144.

Cliffe, S. J. and Motion, B. (2005). Building contemporary brands: A sponsorship-based strategy. Journal of Business Research, 58 (8), 1068-1077.

Cornwell, T. B. (1995). Sponsorship-linked marketing development. Sport Marketing Quarterly, 4 (4), 13-24.

Cornwell, T. B., Weeks, C. S., and Roy, D. P. (2005) Sponsorship-linked marketing: opening the black box. Journal of Advertising 34 (2), 21-42.

Crowther, P. (2010), Marketing space: a conceptual framework for marketing events, The Marketing Review, 10 (4), 369-383.

Davies, F. and Tsiantas, G. (2008). Selection of leveraging strategies by national Olympic sponsors: A proposed model. International Journal of Sports Marketing and Sponsorship 9 (4), 271-289.

Dolphin, R. R. (2003) Sponsorship: perspectives on its strategic role. Corporate Communications: An International Journal 8 (3) 173-186.

Donlan, L. (2010). Sports sponsorship as a tool for customer engagement. Paper presented at Academy of Marketing Conference, July 2010, Coventry, UK. 
Duncan, T. and Moriarty, S.E. (1998), A communication based marketing model for managing relationships, Journal of Marketing, 62 (2), 1-14.

Erdogan, B. Z. and Kitchen, P. J. (1998) Managerial mindsets and the symbiotic relationship between sponsorship and advertising. Marketing and Intelligence Planning 16 (6), 369-374.

Farrelly, F, Quester, P and Burton, R. (2006). Changes in sponsorship value: Competencies and capabilities of successful sponsorship relationships. Industrial Marketing Management 35 (8), 10161026.

Flick, U. (2002) An introduction to qualitative research. (2nd edition), Sage, London.

General Electric (2008) GE launches marketing initiatives of London 2012 Olympic Games.

Available at: http://www.genewscenter.com/content/detail.aspx? releaseid=4317\&newsareaid=2

[Accessed 25 August 2011]

Getz, D. (2007). Event Studies. Elsevier, Oxford.

Grönroos, C. (1994). Quo Vadis, marketing? Toward a relationship marketing paradigm. Journal of Marketing Management 10 (5), 347-360.

Grönroos, C. (1990) Service Management and Marketing: Managing the Moments of Truth in Service Competition, Lexington Books, Lexington, MA.

Grönroos, C., and Ravald, A. (2011). Service as business logic: implications for value creation and marketing. Journal of Service Management 22(1), 5-22.

Haeckel, S. (1999). Adaptive Enterprise: Creating and Leading; Sense-and-Respond Organizations. Boston: Harvard Business School Press.

Harris, K., and Baron, S. (2004). Consumer-to-Consumer Conversations in Service Settings. Journal of Service Research, 6 (6), 287-303.

Hartland, T., Skinner, H. and Griffiths, A. (2005) Tries and conversions: are sports sponsors pursuing the right objectives? International Journal of Sports Marketing \& Sponsorship 6 (3), 164-173.

Jones, S. (2004) Depth interviewing. In C. Seale (ed). Social research methods: A reader, Routledge, Abingdon, pp. 257-268.

Kumar, R. (1997). The role of affect in negotiations: an integrative overview. The Journal of Behavioural Science, 33(1), 84-100.

Levin, A. M., Beasley, F. and Gamble, T. (2004). Brand loyalty of NASCAR fans towards sponsors: The impact of fan identification. International Journal of Sports Marketing \& Sponsorship, 6 (1), 1121.

Mangold, W.G. and Faulds, D.J. (2009) Social media: The new hybrid element of the promotion mix. Business Horizons 52 (4), 357-365.

Meenaghan, T. (1998). Current developments and future directions in sponsorship. International Journal of Advertising, 17 (1), 3-28.

Meenaghan, T. (1991). Sponsorship - legitimising the medium. European Journal of Marketing, 25 (11), 5-10. 
Odendahl, T. and Shaw, A.M. (2002) Interviewing elites. In J. Gubrium and J.A. Holstein (eds) Handbook of interview research: context and method. Sage, Thousand Oaks, CA, pp. 299-316.

Olkkonen, R., Tukkanen, H., and Alajoutsijärvi, K. (2000). Sponsorship as relationships and networks: Implications for research. Corporate Communications: An International Journal, 5 (1), 1218.

Park, C. and Lee, T.M. (2009) Information direction, website reputation and eWOM effect: a moderating role of product type. Journal of Business Research 62 (1), 61-67.

Parsons, E. and Maclaran, P. (2009) Contemporary issues in marketing and consumer behaviour, Butterworth Heinemann, Oxford.

Piercy, N. (2009) Market-led strategic change: transforming the process of going to market. $\left(4^{\text {th }}\right.$ edition). Butterworth-Heineman, London.

Poynter, R. (2008) Facebook: The future of networking with customers. International Journal of Market Research 50 (1), 11-12.

Quester, P. and Farrelly, F. (1998). Brand association and memory decay effects of sponsorship: The case of the Australian Formula One Grand Prix. Journal of Product \& Brand Management, 7 (6), 539556.

Ramaswamy, V. (2011). It's about human experiences... and beyond, to co-creation. Industrial Marketing Management, 40 (2), 195-196.

Reuters (2011) Global sponsorship spending to rise 5.2 pct in 2011, Available at: http://www.reuters.com/article/idUSN1125970320110111 [Accessed 14 January 2011].

Roy, D. P. and Cornwell, T. B. (2004). The effects of consumer knowledge on responses to event sponsorships. Psychology \& Marketing, 21 (3), 185-207.

Roy, D.P and Cornwell, T.B. (1999). Managers' Use of Sponsorship in Building Brands: Service and Product Firms contrasted, International Journal of Sports Marketing \& Sponsorship 1 (6), 345-360.

Skildum-Reid, K., (2003). Last Generation Sponsorship Available at: http://www.powersponsorshipdownloads.com/powersponsorship/LastGenerationSponsorship.pdf [Accessed 17 January 2011].

Sleight, S. (1989). Sponsorship. What it is and how to use it. McGraw-Hill, Maidenhead.

Smith, G. (2004). Brand image transfer through sponsorship: A consumer learning perspective. Journal of Marketing Management, 20 (3/4), 457-474.

Spotsvstripes (2011.) Race season - pancake races in Wrexham. Available at: http://www.spotsvstripes.com/b/news/archive/2011/03/21/race-season-pancake-races-inwrexham.aspx [Accessed 25 August 2011]

Vargo, S. L., and Lusch, R. F. (2008). From goods to service(s): Divergences and convergences of logics. Industrial Marketing Management, 37 (3), 254-259.

Vargo, S.L. and Lusch, R.F. (2004) Evolving to a new dominant logic for marketing, Journal of Marketing, 68 ( 1), 1-17. 
Verity, J. (2002). Maximising the marketing potential of sponsorship for global brands. European Business Journal, 14 (4), 161-173.

Westberg, K., Stavros, C. and Wilson, B. (2008) An examination of the impact of player transgressions on sponsorship b2b relationships, International Journal of Sports Marketing \& Sponsorship 9 (2), 125-134.

Whelan, S. and Wohlfeil, M. (2006). Communicating brands through engagement with 'lived' experiences. Journal of Brand Management 13 (4/5), 313-329.

Wood, E. H. (2009). Evaluating Event Marketing: Experience or Outcome? Journal of Promotion Management, 15 (1), 247-268.

Wood, E. H., and Masterman, G. (2007). Event marketing: Experience and exploitation. Paper presented at the Extraordinary Experiences Conference: Managing the Consumer Experience in Hospitality, Leisure, Sport, Tourism, Retail and Events. 


\section{Appendix 1 - Pre-circulated Interview Questions}

1. What sponsorships are [brand] currently involved in? (select the most high profile/appropriate for further probing)

2. Why have you chosen to use sponsorship over other communications vehicles?

3. How long has the current sponsorship deal been going?

4. How long is the deal in total?

5. Why did you select this particular sponsorship?

6. What choice criteria were used in selecting this sponsorship?

7. Who is the primary target market you are trying to reach through this sponsorship?

8. What are your objectives for the sponsorship of [property]?

a. (if image-related: What images did you want to be transferred? What images are being transferred? How do you know this?)

9. When were the sponsorship objectives set?

10. Are you achieving your stated objectives?

11. How often are the objectives reviewed/re-evaluated? 
12. Who is responsible for setting the sponsorship objectives?

13. What benefits does [brand] get from this sponsorship?

14. What benefits are offered to your consumers through your partnership with [property]?

15. What support activities do you use to exploit/communicate your sponsorship?

16. How closely do you cooperate with the rights holder, e.g. joint promotions, meetings, updates, evaluation?

17. What role does sponsorship play in the wider communications/branding strategy of [brand]?

18. How do you evaluate the success of your sponsorships?

19. What measures do you use to measure sponsorship effectiveness?

20. Who is responsible for sponsorship evaluation (brand, rights holder, agency)?

21. What support, if any, do you get from [property] in terms of evaluation?

22. Do you see sponsorship as playing a long-term role in the communications/brand strategy of [brand]? 
Figure 1: Marketing Space Model

\section{marketing space model}

Events are one element of any organisations integrated marketing communications strategy, therefore preceding this model is a strategic decision to activate marketing events to achieve specific objectives.

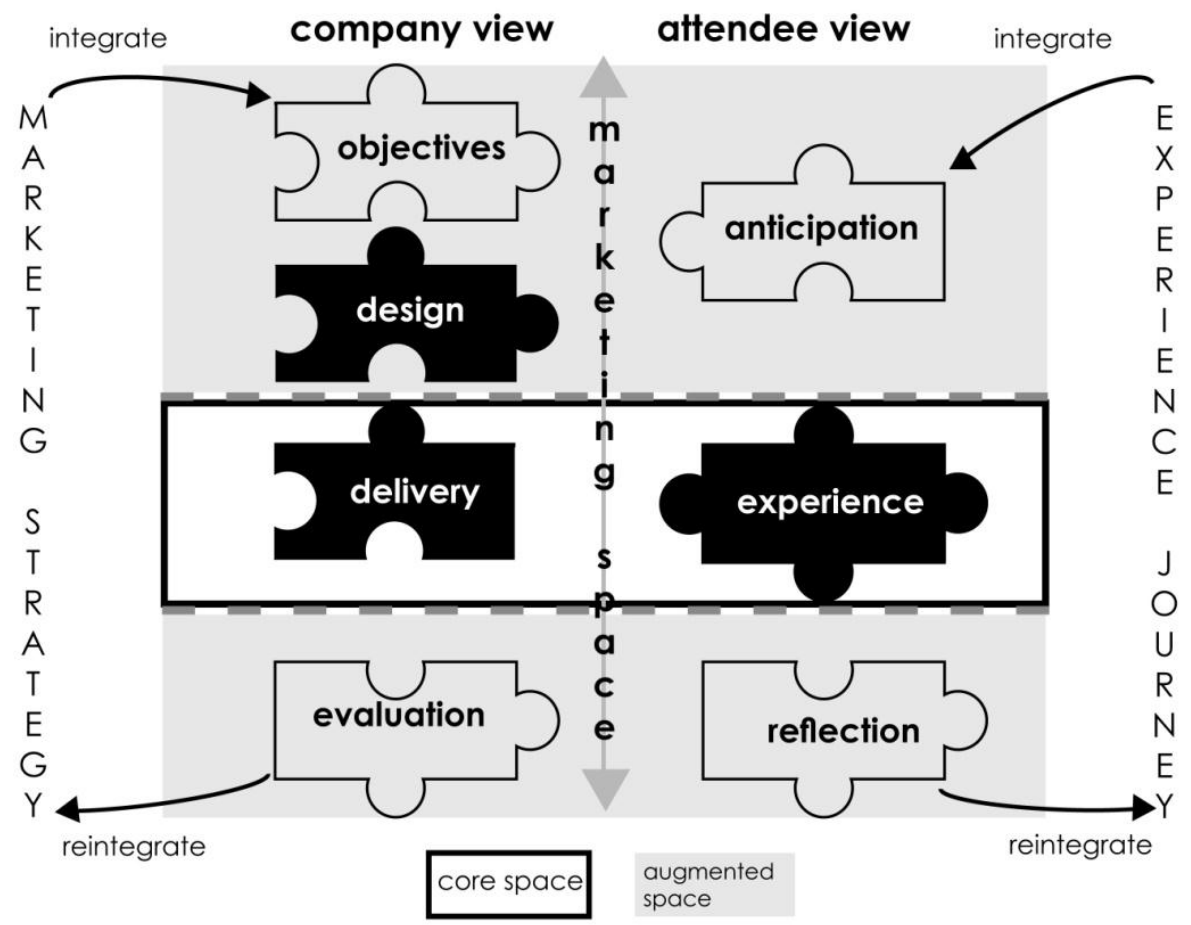

Source: Crowther (2010) 
Figure 2: Marketing Event Platforms

\section{marketing event platforms}

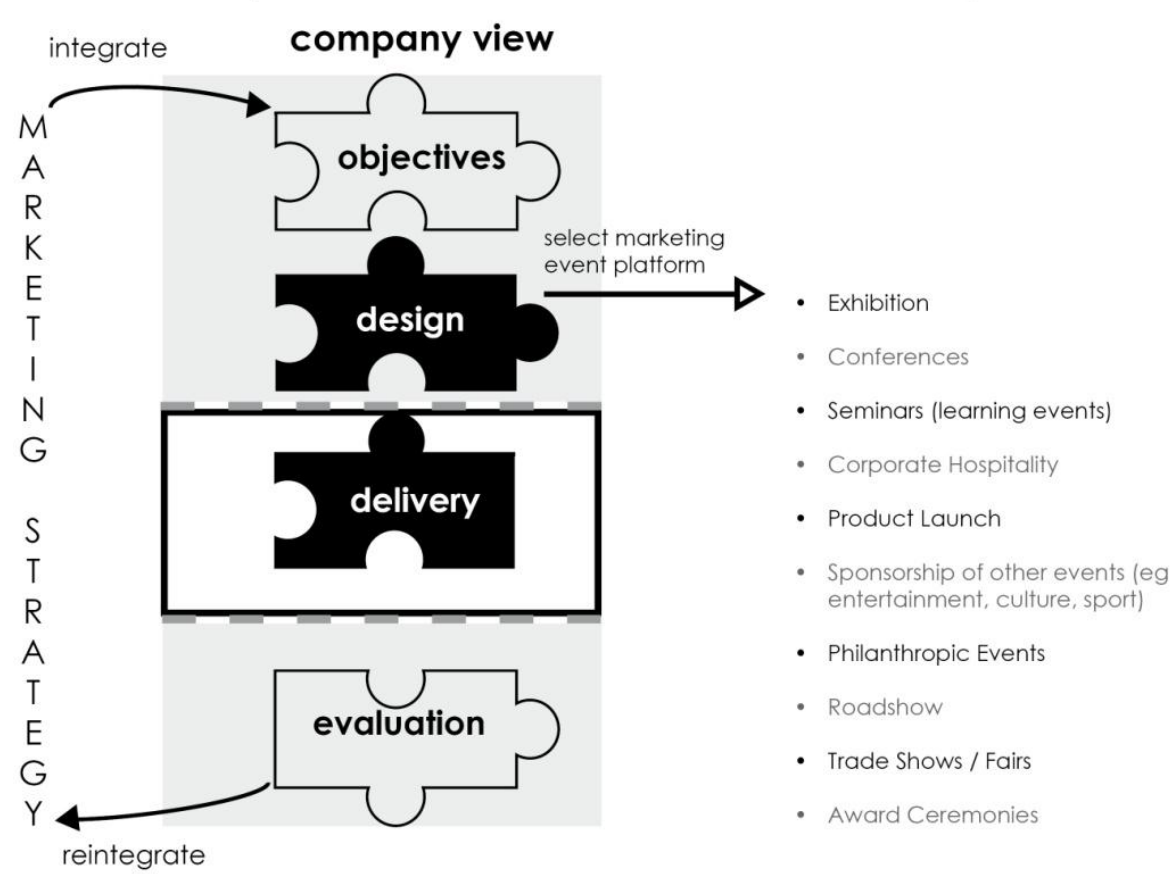

Source: Crowther (2010) 